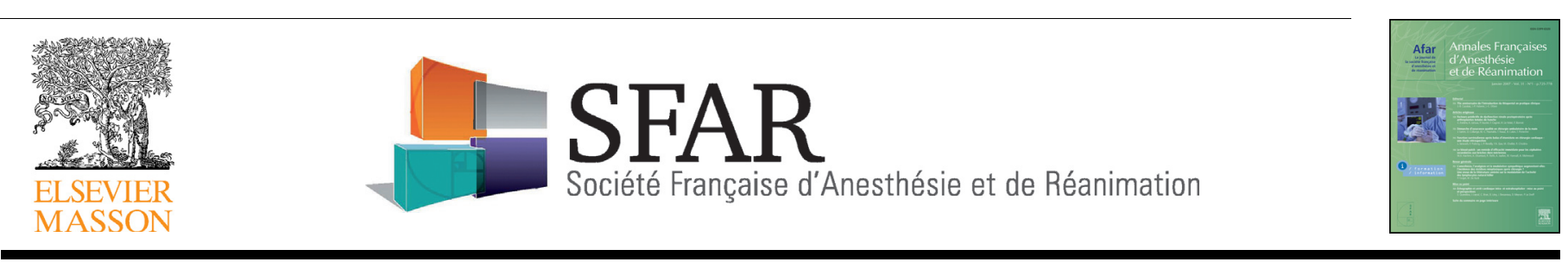

Original article

\title{
Does sevoflurane preserve regional cerebral oxygen saturation measured by near-infrared spectroscopy better than propofol?
}

\section{Le sévoflurane préserve-t-il mieux la saturation cérébrale régionale en oxygène mesurée par la spectroscopie infrarouge que le propofol ?}

\author{
L. Valencia ${ }^{\mathrm{a}, *}$, A. Rodríguez-Pérez ${ }^{\mathrm{a}}$, B. Kühlmorgen ${ }^{\mathrm{a}, \mathrm{b}}$, R.Y. Santana ${ }^{\mathrm{a}, \mathrm{c}}$ \\ ${ }^{a}$ Department of Anaesthesiology, Hospital Universitario de Gran Canaria Doctor Negrín, Barranco de la Ballena s/n., 35010 Las Palmas de Gran Canaria, Spain \\ ${ }^{\mathrm{b}}$ Department of Anaesthesiology, Hospital el Ángel, Málaga, Spain \\ ${ }^{\mathrm{c}}$ Department of Traumatology, Hospital Universitario Insular de Gran Canaria, Las Palmas de Gran Canaria, Spain
}

\section{A R T I C L E I N F O}

\section{Article history:}

Received 31 July 2013

Accepted 30 December 2013

Available online 24 February 2014

\section{Keywords:}

Sevoflurane

Propofol

Cerebral oximetry

Cerebral oxygenation

Monitoring

\begin{abstract}
A B S T R A C T
Objective. - The aim of this study was to compare the effect of sevoflurane and propofol on cerebral oxygenation, using regional cerebral oxygen saturation $\left(\mathrm{SrO}_{2}\right)$ measured by near-infrared spectroscopy (NIRS).

Study design. - Prospective, randomized, controlled study.

Patients and methods. - Fifty-four patients aged between 18 and 65 years who underwent elective minor surgery (tumorectomy for breast cancer or inguinal hernia repair) were randomly assigned to receive sevoflurane or propofol anaesthesia. Exclusion criteria included pre-existing cerebrovascular diseases, anaemia, ASA > III, blood loss $\geq 200 \mathrm{~mL}$, arterial hypotension, baseline pulse oximetry $<97 \%$, sign of sensor low quality of $\mathrm{SrO}_{2}$ or bispectral index, and patients with a forehead area $<6.5 \mathrm{~cm}$. $\mathrm{SrO}$, bispectral index, haemodynamic data and anaesthetic doses were recorded during surgery.

Results. - A total of 48 patients were included in the final analysis ( 24 in each group). There were no significant differences in mean, minimum and maximum $\mathrm{SrO}_{2}$ between sevoflurane and propofol groups. The relative maximum decrease was higher in propofol anaesthesia than sevoflurane anaesthesia $(9.6 \pm 10.7$ versus $4.2 \pm 7.2 \% ; P=0.048)$. Cerebral desaturation $\left(20 \%\right.$ reduction from $\mathrm{SrO}_{2}$ baseline during 15 seconds) occurred in 4 patients in propofol group exclusively $(P=0.109)$. $\mathrm{SrO}_{2}$ adjusted for baseline was higher in the sevoflurane group than in the propofol group $(67.3 \pm 1.8 \%$ versus $64.2 \pm 1.7 \% ; P=0.018)$. There were no significant differences in haemodynamic parameters between the two groups.

Conclusions. - Cerebral cortical oxygenation measured by NIRS may be better preserved with sevoflurane than with propofol. These findings suggest that sevoflurane anaesthesia could be a good option in patients with compromised cerebral oxygenation, given the absence of intracranial hypertension. Further studies with larger sample sizes are required to support our results.

(c) 2014 Société française d'anesthésie et de réanimation (Sfar). Published by Elsevier Masson SAS. All
\end{abstract} rights reserved.

\section{R É S U M É}

Objectif. - L'objectif de cette étude était de comparer l'effet du sévoflurane et du propofol sur l'oxygénation cérébrale, en utilisant la saturation cérébrale régionale en oxygène $\left(\mathrm{SrO}_{2}\right)$ mesurée par la spectroscopie infrarouge (NIRS).

Type d'étude. - Étude prospective, randomisée et contrôlée.

Patients et méthodes. - Cinquante-quatre patients âgés entre 18 et 65 ans programmés pour chirurgie élective mineure (tumorectomie pour cancer du sein ou réparation d'hernie inguinale) ont été assignés après randomisation à recevoir du sévoflurane ou du propofol.

Critère d'exclusion. - Antécédents de maladie cérébrovasculaire, anémie, score ASA $>$ III, saignement $\geq 200 \mathrm{~mL}$, hypotension artérielle, saturation artérielle en oxygène $<97 \%$, mauvais signal $\mathrm{SrO}_{2}$ ou d'index bispectral, et une surface frontale $<6,5 \mathrm{~cm}$. La $\mathrm{SrO}_{2}$, l'index bispectral, les variables hémodynamiques et les doses anesthésiques ont été enregistrés au cours de la chirurgie.

\footnotetext{
* Corresponding author.

E-mail addresses: ori98es@yahoo.es, romenyone@hotmail.com (L. Valencia).
} 
Résultats. - Quarante-huit patients ont été inclus dans l'analyse finale (24 dans chaque groupe). Aucune différence significative n'a été trouvée entre les groupes pour la $\mathrm{SrO}_{2}$ moyenne, minimal et maximal. La baisse maximale de la $\mathrm{SrO}_{2}$ basale était plus importante avec le propofol $(9,6 \pm 10,7 \%$ versus $4,2 \pm 7,2 \%$; $p=0,048$ ). Quatre épisodes de désaturation cérébrale (réduction de $20 \%$ de la $\mathrm{SrO}_{2}$ basale pendant 15 secondes) ont été observés dans le groupe propofol exclusivement $(p=0,109)$. $\mathrm{La} \mathrm{SrO}_{2}$ ajustée à la valeur basale était supérieure avec le sévoflurane par rapport au propofol $(67,3 \pm 1,8 \%$ versus $64,2 \pm 1,7 \%$; $p=0,018$ ). Aucune différence significative des paramètres hémodynamiques n’a été observée entre les deux groupes.

Conclusions. - L'oxygénation cérébrale corticale, mesurée par la NIRS, est probablement mieux conservée par le sévoflurane que le propofol. Ces résultats suggèrent que l'anesthésie au sévoflurane pourrait être une meilleure option chez les patients dont l'oxygénation cérébrale est compromise, à condition qu'il n'y ait pas d'hypertension intracrânienne. D'autres études plus larges sont nécessaires afin de soutenir nos résultats.

(c) 2014 Société française d'anesthésie et de réanimation (Sfar). Publié par Elsevier Masson SAS. Tous droits réservés.

\section{Introduction}

In several surgical procedures and in some clinical situations where there is a risk of cerebral hypoperfusion, the protection of the central nervous system becomes a priority for anaesthesiologists. Under these circumstances, adequate monitoring and the choice of the right anaesthesia can play a fundamental role in the outcome. Both sevoflurane and propofol have neuroprotective properties [1]. However, neither has proved clearly superior in the maintenance of cerebral oxygenation. Studies on human subjects have shown that although both drugs produce a similar decrease in Cerebral Metabolic Rate $\left(\mathrm{CMRO}_{2}\right)$, sevoflurane $(\mathrm{MAC}<1.0)$ reduces cerebral blood flow (CBF) less than propofol [2-5]. This translates to a decrease of $\mathrm{CBF} / \mathrm{CMRO}_{2}$ ratio in the case of propofol, which remains constant when sevoflurane is used [6]. Thus, the cerebral oxygenation balance could be better preserved with sevoflurane than with propofol $[7,8]$.

Near-infrared spectroscopy (NIRS) is a non-invasive technique that provides continuous monitoring of regional cerebral tissue oxygen saturation $\left(\mathrm{SrO}_{2}\right)$. Numerous studies have demonstrated its efficiency in discovering intraoperative silent ischaemic events and improve the results in high-risk surgery, such as cardiac [9], thoracic $[10,11]$ and abdominal surgeries in elderly patients $[12,13]$. Because $\mathrm{SrO}_{2}$ is capable of detecting small changes in cerebral oxygenation reflecting the $\mathrm{CBF} / \mathrm{CMRO}_{2}$ ratio, it is possible to evaluate how cerebral oxygenation is affected by sevoflurane and propofol.

The aim of this study was to determine if NIRS detects differences in $\mathrm{SrO}_{2}$ between sevoflurane or propofol anaesthesia.

\section{Patients and methods}

Approval for this randomised, controlled study was provided by the Ethical Committee of the Hospital Universitario de Gran Canaria Doctor Negrín, Las Palmas de Gran Canaria, Spain (chairperson Professor Dr S. Ruiz) on 12 September 2009 (registration number 09/021). After written informed consent, 54 patients aged between 18 and 65 years who underwent elective minor surgery (tumorectomy for breast cancer or inguinal hernia repair) were randomly assigned to receive sevoflurane (group S) or propofol (group P) anaesthesia between September 2009 and February 2010. Simple randomisation was carried out using a random number table generator. Numbers were distributed in sealed, opaque envelopes which were opened at the beginning of anaesthesia. Non-inclusion criteria were pre-existing cerebrovascular diseases, ASA physical status $\geq \mathrm{IV}$, anaemia according to WHO criteria (haemoglobin in females $<12 \mathrm{~g} / \mathrm{dL}$ and in males $<13 \mathrm{~g} / \mathrm{dL}$ ) and patients with a forehead area $<6.5 \mathrm{~cm}$ because it was impossible to attach both sensors. Exclusion criteria included baseline peripheral oxygen arterial saturation $\left(\mathrm{SpO}_{2}\right)$ less than $97 \%$, low quality signs of $\mathrm{SrO}_{2}$ or bispectral index (BIS), bleeding more than $200 \mathrm{~mL}$ or haemodynamic instability (decrease of $25 \%$ of baseline mean arterial pressure [MAP] for three minutes).

No premedication was administered. Monitoring included electrocardiography, $\mathrm{SpO}_{2}$, non-invasive arterial pressure measurement (Cicero EM PM8060 ${ }^{\mathrm{TM}}$, Dräger, Lübeck, Germany), bispectral index (BIS VISTA Aspect Medical Systems ${ }^{\mathrm{TM}}$, Massachusetts, USA) and $\mathrm{SrO}_{2}$ using INVOS $5100 C^{\mathrm{TM}}$ (Covidien, Dublin, Ireland). The $\mathrm{SrO}_{2}$ sensors were placed in the superior supraorbital margins, on top of those BIS electrodes. Before recording the data, we checked for a good signal, free of artefacts on both monitors, using Signal Quality Index (ICS) for BIS and the Signal Strength Indicator (SSI) for $\mathrm{SrO}_{2}$.

During the surgical procedure, the degree of neuromuscular blockade was logged (TOF Watch ${ }^{\mathrm{TM}}$, Organon Teknika, Durhman, USA), as well as the inspired and expired oxygen fractions, endtidal carbon dioxide tension $\left(\mathrm{ETCO}_{2}\right)$, concentration of sevoflurane and tympanic temperature (Genius $2^{\mathrm{TM}}$, Covidien, Dublin, Ireland). The latter was maintained between 35 and $36{ }^{\circ} \mathrm{C}$ using a warming blanket (Warm Touch $5300^{\mathrm{TM}}$, Nellcor, UK).

After full preoxygenation, all patients in group $S$ received fentanyl $(2 \mu \mathrm{g} / \mathrm{kg})$, before vital capacity induction with sevoflurane $8 \%$ (SIBI connector ${ }^{\mathrm{TM}}$, Ventitech Medical Device, Quebec, Canada). Cisatracurium $(0.2 \mathrm{mg} / \mathrm{kg})$ after loss of verbal response was administered. In group $\mathrm{P}$, anaesthesia was induced with fentanyl ( $2 \mu \mathrm{g} / \mathrm{kg}$ ), propofol ( $2 \mathrm{mg} / \mathrm{kg}$ ) and cisatracurium $(0.2 \mathrm{mg} /$ $\mathrm{kg}$ ). In all cases, orotracheal intubation was performed three minutes after injection of the neuromuscular blocker and connected to mechanical ventilation (workstation Dräger Cicero $\mathrm{EM}^{\mathrm{TM}}$, Lübeck, Germany), with the following parameters: tidal volume $7 \mathrm{~mL} / \mathrm{kg}$, respiration rate $12-\mathrm{c} / \mathrm{min}$, inspiration-expiration ratio 1:2, oxygen/air mix (40/60\%). Afterwards, minute volume was adjusted to obtain an $\mathrm{ETCO}_{2}$ of between $30-34 \mathrm{mmHg}$.

Anaesthesia was maintained with propofol $(4-8 \mathrm{mg} / \mathrm{kg} / \mathrm{h})$ or sevoflurane (1-2\% end-tidal concentration) according to group. Propofol was administered to obtain BIS values of between 40 and 60 . Both groups used remifentanyl with doses of between 0.05$0.3 \mu \mathrm{g} / \mathrm{kg} / \mathrm{min}$ at the anaesthesiologist's discretion. Neuromuscular blockade was achieved with cisatracurium bolus, maintaining one or two responses in a train-of-four stimulation. Five milligrams of intravenous ephedrine was administered when the MAP decreased to less than $25 \%$ of baseline values.

Previous to induction, the following baseline values were recorded while the patient breathed room air: MAP, heart rate $(\mathrm{HR}), \mathrm{SpO}_{2}$, BIS and $\mathrm{SrO}_{2}$. These variables were recorded every minute during the first five minutes after induction. Afterwards, until perfusion of propofol or sevoflurane was suspended at the end of surgery, the same data was collected every five minutes. Furthermore, the propofol dose used or expired fraction of sevoflurane was noted each minute. Cerebral oxygen desaturation 
was defined as a decline in $\mathrm{SrO}_{2}$ more than $20 \%$ from baseline for more than $15 \mathrm{~s}$. Data were recorded by an independent investigator.

\subsection{Statistical analysis}

Sample size was chosen based on a pilot sample of 12 subjects. Differences in $\mathrm{SrO}_{2}$ adjusted for a baseline value of three units was found $(3.1 \pm 1.5 \%)$. With these data, and assuming $80 \%$ strength and an alpha level of 0.05 , a sample size for 24 patients in each group was calculated. We expected to detect a difference of $5 \%$ in a design with repeated measurements. Data from the pilot study were not included in the present study.

In the descriptive analysis of quantitative variables, the mean and standard deviation (S.D.) were used. The mean differences were analyzed using Student's $T$ test for quantitative variables in those cases in which those variables followed a normal distribution. Distribution was evaluated by Kolmogorov-Smirnoff's $Z$ test. Differences in proportion were carried out with contingency analysis using Chi-square and by Fisher's exact test when needed. A mixed-model repeated-measure analysis compared the effect of sevoflurane on $\mathrm{SrO}_{2}$ adjusted for baseline over the surgery period. The $U$ Mann-Whitney's test was used for the differences in MAP, $\mathrm{HR}, \mathrm{BIS}$ and $\mathrm{SrO}_{2}$ each time with respect to baseline value and between both groups. A $P$-value $<0.05$ was considered statistically significant. Statistical analysis was performed using the SPSS-PC statistical software program (version 15.0; SPSS, Inc., Chicago, IL, USA).

\section{Results}

Fifty-four patients between 18 and 65 years scheduled for breast cancer tumorectomy (22 patients) or inguinal hernia repair (32 patients) were considered for the study. Four patients did not meet inclusion criteria (one because of pre-existing cerebrovascular disease, another due to anaemia, and two more because it was impossible to place the $\mathrm{SrO}_{2}$ and $\mathrm{BIS}$ sensors). No patients declined to participate. After randomization, one patient in group $S$ and another in group P bled more than $200 \mathrm{~mL}$ or suffered an episode of arterial hypotension for more than three minutes respectively. These patients were also excluded from the final analysis. Twenty-four patients in each group completed the study. There were no differences in demographic and intraoperative data between the groups (Table 1 ).

Table 2 shows the preoperative haemodynamic variables, $\mathrm{SrO}_{2}$ and baseline $\mathrm{SpO}_{2}$. There were no significant statistical differences
Table 2

Preoperative cerebral oximetry values, baseline pulse oximetry and baseline haemodynamic data.

\begin{tabular}{llll}
\hline & $\begin{array}{l}\text { Propofol } \\
(n=24)\end{array}$ & $\begin{array}{l}\text { Sevoflurane } \\
(n=24)\end{array}$ & P-value \\
\hline Baseline $\mathrm{SrO}_{2}(\%)$ & $63.4 \pm 9.9$ & $61.4 \pm 11$ & 0.52 \\
Mean arterial pressure (mmHg) & $92.7 \pm 12.2$ & $98.1 \pm 13.9$ & 0.16 \\
Baseline pulse oximetry (\%) & $99.3 \pm 1$ & $99.5 \pm 1.1$ & 0.32 \\
Heart rate (b/min) & $72.1 \pm 12.9$ & $77.9 \pm 14$ & 0.14 \\
\hline
\end{tabular}

Data are mean \pm S.D.

between the groups. The end-tidal sevoflurane concentrations ranged between 3.2 and $2.4 \%$ in the group $\mathrm{S}$ during inhalation induction and between 1.3 and $1.7 \%$ during surgery. In group P, a maintenance dose of $4.7 \pm 0.7 \mathrm{mg} / \mathrm{kg} / \mathrm{h}$ was used. BIS (mean \pm S.D.) did not differ between the groups $(49.9 \pm 4.2$ in group $S$ and $46.1 \pm 6.1$ in group $P$; $P=0.13)$. However, the BIS values were superior in group $S$ in the induction (minutes 1,2 and 3) and at minute 70 (Fig. 1).

The mean, minimum and maximum values of $\mathrm{SrO}_{2}$ reached were similar in both groups (Table 3 ). The maximum decrease of $\mathrm{SrO}_{2}$ with respect to its baseline values was calculated, obtaining a higher decrease of five points in group P compared with group S $(9.6 \pm 10.7 \%$ versus $4.2 \pm 7.2 \% ; P=0.048)$. Patients' $\mathrm{SrO}_{2}$ data were compared between both groups using a mixedmodel ANCOVA. We noted that $\mathrm{SrO}_{2}$ depended on their baseline value, since patients with higher baseline levels tended to have higher means. When the $\mathrm{SrO}_{2}$ values were adjusted for baseline, it was observed that the predicted mean $\mathrm{SrO}_{2}$ for each patient did not depend only on the baseline $\mathrm{SrO}_{2}$, but also on the anaesthetic used $\left(\mathrm{SrO}_{2}=66.76+3.04 \times\right.$ sevoflurane +0.968 [baseline $\left.\left.\mathrm{SrO}_{2}-62.4\right]\right)$. The results of the covariance analysis showed the adjusted mean $\mathrm{SrO}_{2}$ was lower in group $\mathrm{P}(64.2 \pm 1.7 \%)$ than group $\mathrm{S}(67.3 \pm 1.8 \%)$. This was a significant statistical difference $(P=0.018)$.

When comparing the groups' mean $\mathrm{SrO}_{2}$ at each data collection point, there were no differences between the groups (Fig. 2). Up to the first 15 minutes in both groups significant superior $\mathrm{SrO}_{2}$ values were found with respect to baseline value. These differences in the group $S$ persisted until the 25th minute. Four patients in group $P$ had episodes of cerebral desaturation while group $S$ had none $(P=0.109)$. These events occurred during the anaesthetic maintenance phase, without regard to changes in MAP, HR or BIS.

Haemodynamic variables are represented in Figs. 3 and 4. In both groups, there was a decrease in MAP $(16 \pm 4.2 \%$ in group $P$ versus $9 \pm 17.2 \%$ in group $S ; P=0.06$ ) with respect to values previous to the induction. There were no significant statistical

Table 1

Demographic variables and intraoperative variables.

\begin{tabular}{|c|c|c|c|}
\hline & Propofol $(n=24)$ & Sevoflurane $(n=24)$ & $P$-value \\
\hline Age (years) & $43.4 \pm 12.9$ & $50.6 \pm 12.6$ & 0.076 \\
\hline Body mass index $\left(\mathrm{kg} / \mathrm{m}^{2}\right)$ & $27.2 \pm 5.6$ & $27.5 \pm 5.6$ & 0.78 \\
\hline Male/female & $6 / 18$ & $7 / 17$ & 0.75 \\
\hline Haemoglobin $(g / d L)$ & $13.2 \pm 1.4$ & $12.8 \pm 1.3$ & 0.65 \\
\hline ASA physical status (I/II/III) & $7 / 16 / 1$ & $4 / 17 / 1$ & 0.42 \\
\hline \multicolumn{4}{|l|}{ Underlying diseases } \\
\hline Chronic obstructive pulmonary disease & 4 & 4 & 1 \\
\hline Renal insufficiency & 0 & 2 & 0.49 \\
\hline Arterial hypertension & 4 & 10 & 0.06 \\
\hline Diabetes mellitus & 1 & 4 & 0.35 \\
\hline Duration of anaesthesia (minutes) & $96.1 \pm 19.2$ & $102.1 \pm 16.2$ & 0.24 \\
\hline Fluid administered ( $m L)$ & $1095 \pm 554$ & $1050 \pm 510$ & 0.77 \\
\hline
\end{tabular}

Data are mean \pm S.D. or numbers. 


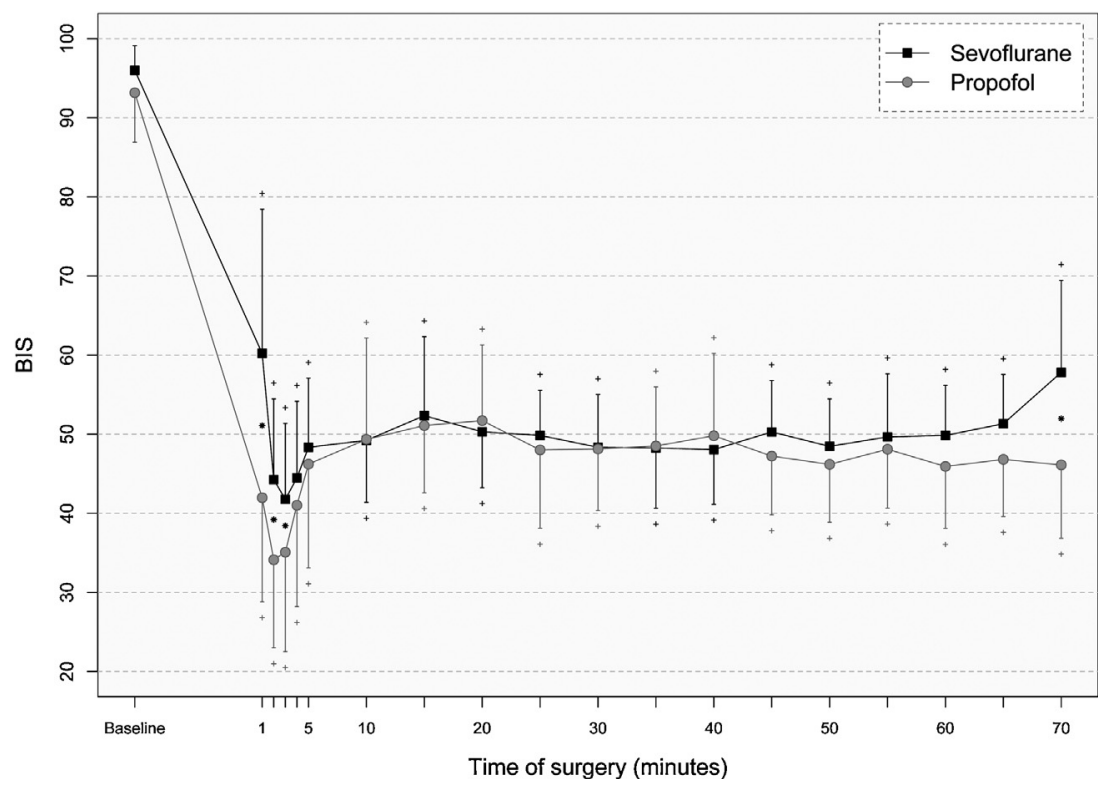

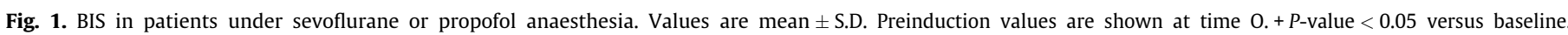
${ }^{*} P$-value $<0.05$ between sevoflurane and propofol groups. The numbers of patients decreased in both groups from 24 at baseline to 22 at 70 minutes. BIS: bispectral index.

Table 3

$\mathrm{SrO}_{2}$ values in propofol and sevoflurane groups.

\begin{tabular}{lcll}
\hline & Propofol $(n=24)$ & Sevoflurane $(n=24)$ & $P$-value \\
\hline Mean $\mathrm{SrO}_{2}(\%)$ & $64.8 \pm 11.5$ & $65.9 \pm 10.4$ & 0.73 \\
Minimum $\mathrm{SrO}_{2}(\%)$ & $57.4 \pm 12.3$ & $58.6 \pm 10.6$ & 0.71 \\
Maximum $\mathrm{SrO}_{2}(\%)$ & $75.3 \pm 11.2$ & $76.4 \pm 10.1$ & 0.74 \\
Relative maximum $_{\text {decrease } \mathrm{SrO}_{2}(\%)}$ & $9.6 \pm 10.7$ & $4.2 \pm 7.2$ & 0.04 \\
$\begin{array}{c}\text { Mean value of } \mathrm{SrO}_{2} \\
\text { adjusted for baseline (\%) }\end{array}$ & $64.2 \pm 1.7$ & $67.3 \pm 1.8$ & 0.018 \\
\hline
\end{tabular}

Data are mean \pm S.D.

differences when comparing mean MAP values between the groups $(81 \pm 9.1$ in group $S$ and $81.7 \pm 8.1$ in group $P ; P=0.79$ ). At 1 and 2 minutes, MAP was statistically higher in group $S$ than group $P$, while at 40 minutes it was lower than group P (Fig. 3). Significant differences in recorded MAP were found in both groups with respect to baseline values during data collection. Mean \pm S.D. heart rates were very similar in groups $\mathrm{S}$ and $\mathrm{P}(66.7 \pm 11.5$ and $67.4 \pm 8.1$, respectively) without statistical differences $(P=0.791)$. At minutes 10,30 and 40, heart rate was significantly higher in group P (Fig. 4).

\section{Discussion}

The results obtained in the present study indicate that $\mathrm{SrO}_{2}$ values adjusted for baseline during sevoflurane anaesthesia were significantly higher than those observed during propofol anaesthesia. Also, the maximum decrease in $\mathrm{SrO}_{2}$ with respect to baseline values was more pronounced in group $\mathrm{P}$ than group $\mathrm{S}$. In group $\mathrm{P}$, there were 4 episodes of cerebral desaturation, while there were none in group $\mathrm{S}$. These results highlight the fact that sevoflurane decreases CBF less than propofol compared with the

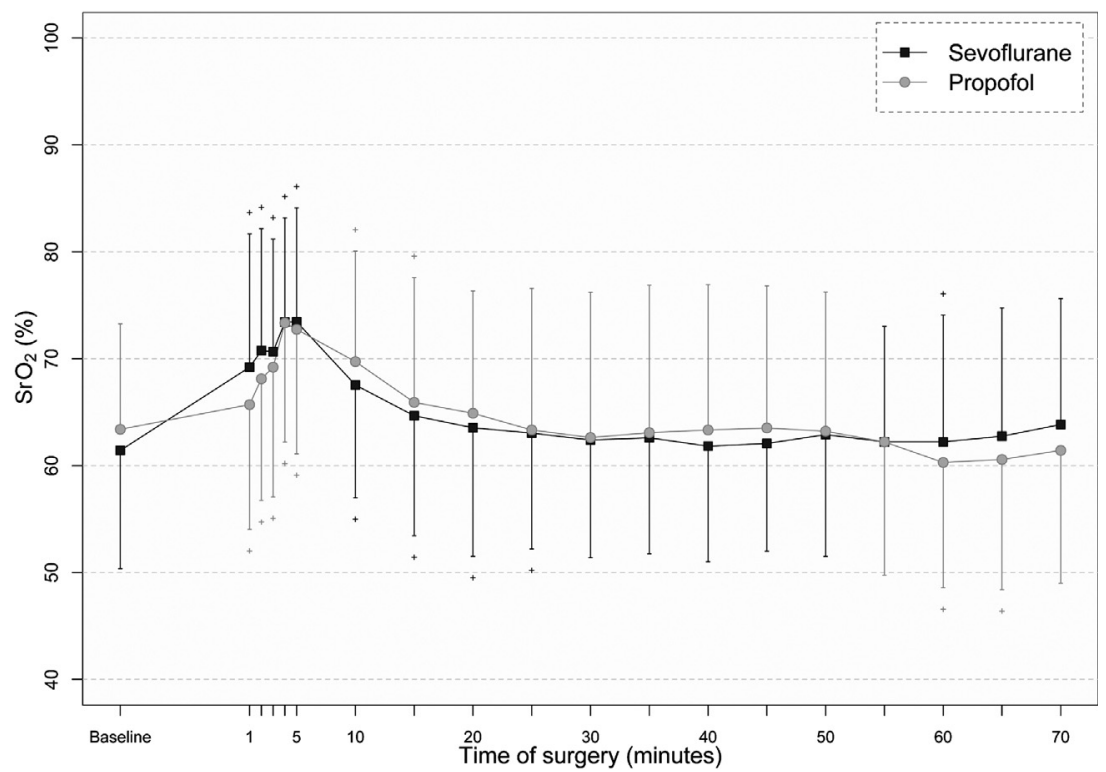

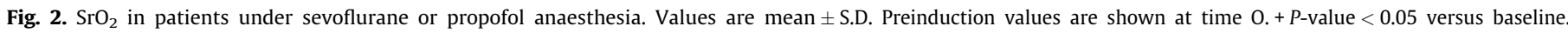

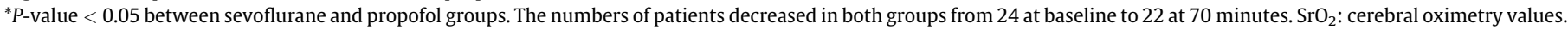




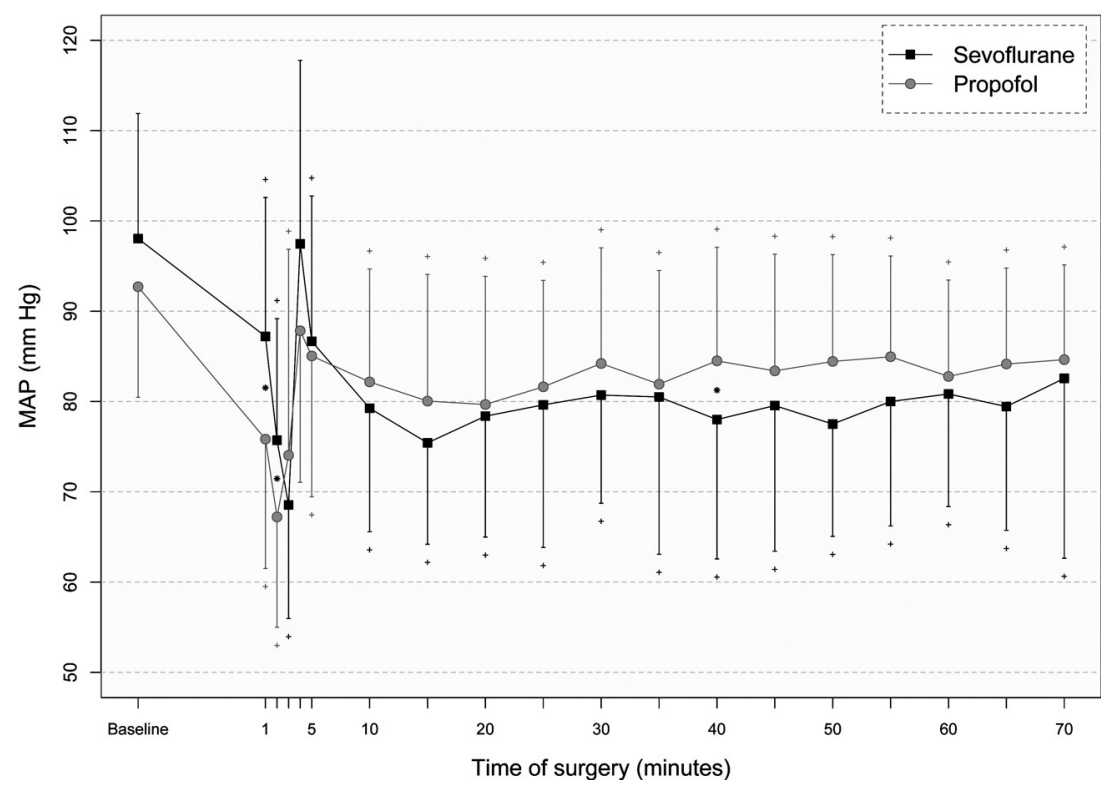

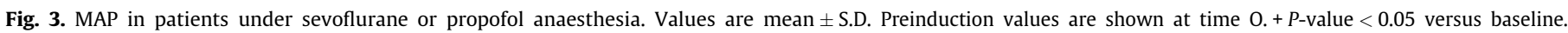

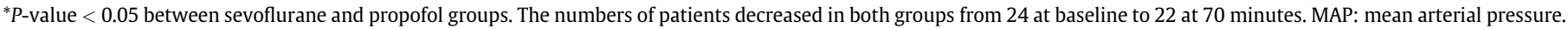

decrease in $\mathrm{CMRO}_{2}$ that both produce. Inhalational anaesthetic agents alter the cerebral autoregulation in a dose-dependent way, and are not able to maintain the coupling between the $\mathrm{CBF}$ and $\mathrm{CMRO}_{2}$ [14]. However, today we know that sevoflurane at concentrations lower than 1.5 MAC maintains the coupling between $\mathrm{CBF}$ and $\mathrm{CMRO}_{2}$, the same as what occurs with propofol $[15,16]$. Not only is the $\mathrm{CBF} / \mathrm{CMRO}_{2}$ ratio more well preserved with sevoflurane, but its coupling at anaesthetic levels is also guaranteed.

The global effect of sevoflurane and propofol on cerebral oxygenation has already been studied on other occasions by monitoring jugular venous bulb oxygen saturation $\left(\mathrm{SjO}_{2}\right)$. The results of these studies have shown a tendency to obtain higher values of $\mathrm{SjO}_{2}$ with the use of sevoflurane. The majority of authors agree with us that sevoflurane maintains a constant ratio of $\mathrm{CBF} / \mathrm{CMRO}_{2}$ and thus maintains oxygenation in cerebral tissue
$[6-8,17,18]$. $\mathrm{SjO}_{2}$ and $\mathrm{SrO}_{2}$ are sensitive and specific instruments for detecting cerebral ischaemia [7]. However, studies that have used $\mathrm{SrO}_{2}$ have not found any differences between sevoflurane and propofol. Both Yoshitani et al. [7] in patients who underwent total hip arthroplasty and Jeong et al. [19] in arthroscopic shoulder surgery in beach chair position detected no differences in $\mathrm{SrO}_{2}$ with different anaesthetic agents. This could be due to various reasons. First, in both studies nitrous oxide was added to sevoflurane during the maintenance phase. It has been noted that when nitrous oxide is added to sevoflurane, important changes occur in cerebral haemodynamics, restoring CBF to levels similar to a waking state [20]. Moreover, high concentrations of nitrous oxide (70\%) are also capable of increasing $\mathrm{CMRO}_{2}$ [2]. Therefore, although the effect of nitrous oxide on $\mathrm{SrO}_{2}$ has not been studied concretely, it seems evident that the use of nitrous oxide influences $\mathrm{SrO}_{2}$ values. Second, a study in 2011 showed that

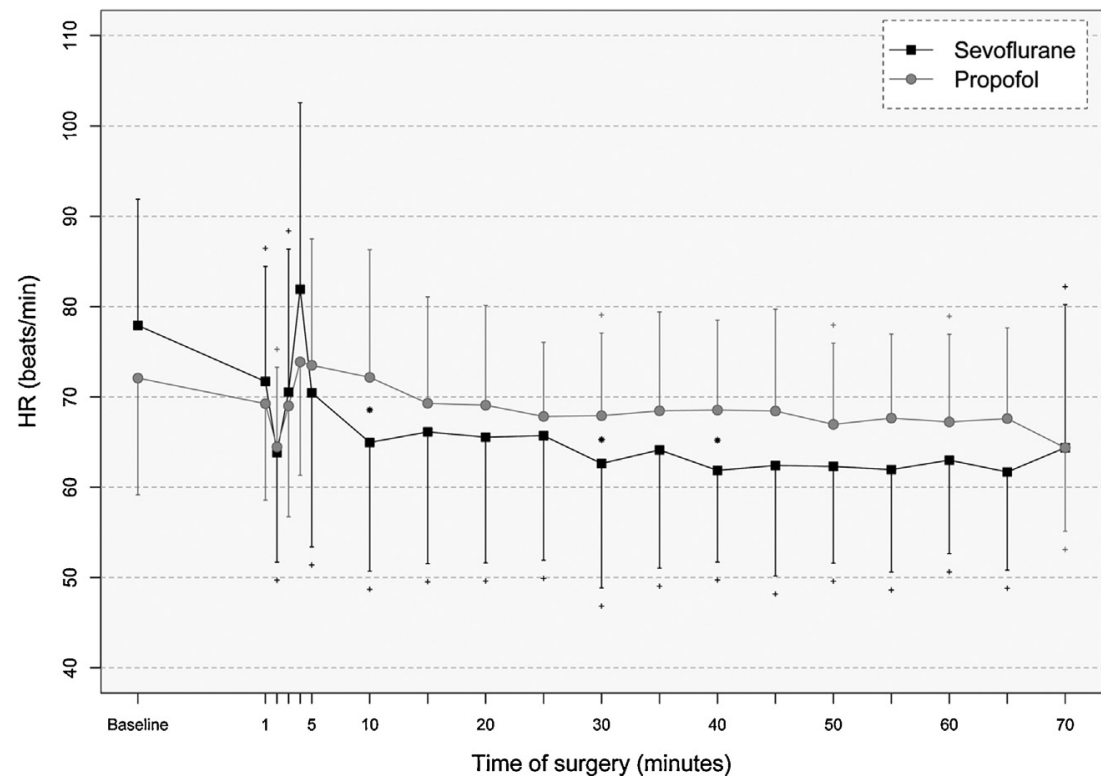

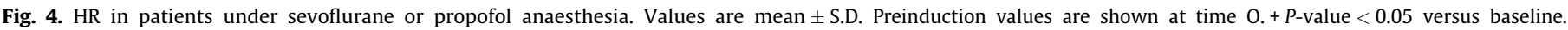
${ }^{*} P$-value $<0.05$ between sevoflurane and propofol groups. The numbers of patients decreased in both groups from 24 at baseline to 22 at 70 minutes. HR: heart rate. 
propofol has a differential effect on cerebral blood vessels, conserving cerebral oxygen saturation in the frontal cortex [21]. These findings suggest that cerebral metabolic demand may be reduced by propofol administration in cortical regions [22]. Third, in both studies there were clinical circumstances that could affect the values of $\mathrm{SrO}_{2}$, masking the effect of the anaesthetic drugs on cerebral oxygenation. In the Yoshitani et al. [7] study, the loss of haemoglobin revealed a significant decrease in $\mathrm{SrO}_{2}$. Surgery in beach chair position in the Jeong et al. [19] study produced a decrease in $\mathrm{CBF}$, consequently altering recorded values of $\mathrm{SrO}_{2}$.

In this study, we controlled the variables that influence $\mathrm{SrO}_{2}$, including the type of anaesthetic used and the necessary dosage to obtain an adequate hypnotic level through BIS [23]. Group $S$ received sevoflurane for both induction and maintenance of anaesthesia. We did this to avoid mixing hypnotics that could skew the results. Although vital capacity inhalatory induction has not been popular due to its adverse respiratory effects, sevoflurane permits a rapid and well-tolerated induction [24].

The remaining variables that could have an influence on $\mathrm{SrO}_{2}$ were precisely those that affected the balance of supply and demand of cerebral oxygen. In this way, we excluded circumstances that did not guarantee a supply of oxygen to the brain, such as procedures that caused bleeding, haemodynamic instability and changes in surgical position. By doing this, we optimized some adequate levels of inspired oxygen content and arterial carbon dioxide concentrations, monitoring pulse oximetry and $\mathrm{ETCO}_{2}$. With respect to factors that modulated the demand of cerebral oxygen, we recorded anaesthetic depth and temperature.

One of the limitations of $\mathrm{SrO}_{2}$ is the lack of normal universal threshold. The most common limit is a relative decrease of $15-20 \%$ with respect to baseline [25] or $\mathrm{SrO}_{2}<50$ or $55 \%$ in absolute values [26]. The results of our study are expressed in values that refer to baseline $\mathrm{SrO}_{2}$ since we used a relative oximeter (INVOS $5100 C^{\mathrm{TM}}$, Covidien, Dublin, Ireland). However, FORE-SIGHT ${ }^{\mathrm{TM}}$ (CAS Medical Systems, Brandford, USA), another $\mathrm{SrO}_{2}$ monitor, offers better technology for providing absolute real values [27]. Unfortunately, there are very few published studies on this monitor [11].

With this aforementioned definition of an episode of cerebral desaturation, we find an $8 \%$ incidence. Compared to other works, the percentage of these events was lower. Casati et al., in two prospective studies on patients of advanced age during major abdominal surgery, obtained a cerebral desaturation of between 20 and 26\% [12,13]. In arthroscopic shoulder surgery, the figures increased to $80 \%$ at the moment that the patient was placed in the beach chair position $[28,29]$. Also, in thoracic surgery during onelung ventilation, the percentage is around $80 \%$ [30]. Some authors used a different threshold than ours to determine an episode of cerebral desaturation. Casati et al. [12,13] defines it as when $\mathrm{SrO}_{2}$ falls below $25 \%$ of baseline value or $20 \%$ when the $\mathrm{SrO}_{2}$ record is less than 50\%. In arthroscopic shoulder surgery, Moerman et al. used a decrease of $20 \%$ with respect to baseline $\mathrm{SrO}_{2}$ or a $50 \%$ absolute value of $\mathrm{SrO}_{2}$ [28]. Another discrepancy is that in some studies the baseline $\mathrm{SrO}_{2}$ is not indicated as previous to induction. It is considered as when the patient is anaesthetised [30]. Finally, not all studies define the duration of the decrease of $\mathrm{SrO}_{2}$ as an episode of cerebral desaturation, although many specify a duration of $15 \mathrm{~s}$. Apart from the definition of chosen cerebral desaturation, the majority of these studies involved elderly patients and surgeries with a high probability of neurological complications. Given that our patients were less than 65 years old and underwent surgery with low risk of cerebral hypoperfusion, it is reasonable that the number of episodes of cerebral desaturation was lower than what has been reported.

As to haemodynamic variables, our results showed no clear differences in MAP and HR between the two groups. Up to now, neither propofol nor sevoflurane have demonstrated a superior haemodynamic stability, and there is a lot of variability. As to HR, the studies are not clear either, although some have shown that propofol generated a decrease in HR compared to sevoflurane [31].

The present study has various limitations. First, we did not measure carbon dioxide values in arterial blood because we based our procedure on $\mathrm{ETCO}_{2}$ levels. Minimal changes in arterial blood $\mathrm{CO}_{2}$ concentrations caused large variations in $\mathrm{CBF}$, and as a consequence in the cerebral oxygenation. However, we decided not to place an arterial catheter due to its invasiveness and potential complications. Second, our main objective was the $\mathrm{SrO}_{2}$ values, without evaluating other results with high clinical relevance such as postoperative neurocognitive deficits. There are studies that relate a lower intraoperative $\mathrm{SrO}_{2}$ with the appearance of postoperative cognitive deficits [11]. In our study, surely the magnitude of $\mathrm{SrO}_{2}$ changes observed in groups $\mathrm{P}$ and $S$ would not have been large enough to be clinically relevant. Nevertheless, these small differences could be significant in other circumstances where the oxygen supply is critical. Third, although there were no significant differences in mean BIS, in the first minutes BIS values were higher in group S. Inhalatory induction can be slower than when done with propofol. Therefore, low deep anaesthesia levels increase cerebral metabolism and the $\mathrm{CMRO}_{2}$, thus increasing the $\mathrm{SrO}_{2}$ values [32]. Fourth, the use of targetcontrolled infusion (TCI) in the case of propofol, or age-adjusted MAC in the case of sevoflurane, would have permitted us to control the anaesthesia dosage in a more exact way. Finally, cerebral oxygenation monitoring with NIRS is not widely accepted because it presents some limitations. There is a wide variability in normal values because of extra-cerebral contamination (scalp, cranium and cerebrospinal fluid). Because is a regional monitor, may fail in detecting ischemia areas distant to the site of sensor placement [26].

\section{Conclusion}

This is the first study demonstrating that, when measured by NIRS, cerebral cortical oxygenation may be better preserved with sevoflurane than with propofol. Therefore, sevoflurane anaesthesia may provide cerebral oxygenation better than propofol. The same evidence was discovered using $\mathrm{SjO}_{2}$. The agreement of the results of two different cerebral oxygen monitoring methods using different technology is an important step in reaching a causal link, which supports our hypothesis.

These findings suggest that sevoflurane offers a margin of safety in patients whose cerebral oxygenation is compromised. Therefore, sevoflurane presents a favourable cerebral haemodynamic effect. This could be a better anaesthetic option in situations where the balance between oxygen supply and demand is affected. However, we should emphasize that in our study patients with endocranial hypertension were not included. For that reason, our results do not extend to patients with brain injury, especially those with endocranial hypertension. In those cases, propofol is preferable to sevoflurane, because it respects cerebral haemodynamics without affecting intracranial pressure [33].

More studies with larger sample sizes are needed to confirm our hypothesis. It would also be interesting to study the small incidences of cerebral desaturation episodes observed with sevoflurane which reflect a decrease in postoperative cognitive deficits, at least in patients at risk for cerebral hypoperfusion.

\section{Disclosure of interest}

The authors declare that they have no conflicts of interest concerning this article. 


\section{Acknowledgements}

Assistance with the study: the authors wish to thank Miguel A. García for his statistical cooperation.

\section{References}

[1] Hans P, Bonhomme V. Why we still use intravenous drugs as the basic regimen for neurosurgical anaesthesia. Curr Opin Anaesthesiol 2006;19:498-503.

[2] Kaisti KK, Langsjo JW, Aalto S, Oikonen V, Teras M, Hinkka S, et al. Effects of sevoflurane, propofol, and adjunct nitrous oxide on regional cerebral blood flow, oxygen consumption, and blood volume in humans. Anesthesiology 2003;99:603-13.

[3] Mielck F, Stephan H, Weyland A, Sonntag H. Effects of one minimum alveolar anaesthetic concentration sevoflurane on cerebral metabolism, blood flow, and $\mathrm{CO}_{2}$ reactivity in cardiac patients. Anesth Analg 1999;89:364-9.

[4] Manohar M. Regional brain blood flow and cerebral cortical $\mathrm{O}_{2}$ consumption during sevoflurane anaesthesia in healthy isocapnic swine. J Cardiovasc Pharmacol 1986;8:1268-75.

[5] Scheller MS, Tateishi A, Drummond JC, Zornow MH. The effects of sevoflurane on cerebral blood flow, cerebral metabolic rate for oxygen, intracranial pressure, and the electroencephalogram are similar to those of isoflurane in the rabbit. Anesthesiology 1988;68:548-51.

[6] Kawano Y, Kawaguchi M, Inoue S, Horiuchi T, Sakamoto T, Yoshitani K, et al. Jugular bulb oxygen saturation under propofol or sevoflurane/nitrous oxide anaesthesia during deliberate mild hypothermia in neurosurgical patients. J Neurosurg Anesthesiol 2004;16:6-10.

[7] Yoshitani K, Kawaguchi M, Iwata M, Sasaoka N, Inoue S, Kurumatani N, et al. Comparison of changes in jugular venous bulb oxygen saturation and cerebral oxygen saturation during variations of haemoglobin concentration under propofol and sevoflurane anaesthesia. Br J Anaesth 2005;94:341-6.

[8] Liao R, Li J, Liu J. Volatile induction/maintenance of anaesthesia with sevoflurane increases jugular venous oxygen saturation and lumbar cerebrospina fluid pressure in patients undergoing craniotomy. Eur J Anaesthesiol 2010; 27:369-76.

[9] Murkin JM, Adams SJ, Novick RJ, Quantz M, Bainbridge D, Iglesias I, et al. Monitoring brain oxygen saturation during coronary bypass surgery: a randomized, prospective study. Anesth Analg 2007;104:51-8.

[10] Kazan R, Bracco D, Hemmerling TM. Reduced cerebral oxygen saturation measured by absolute cerebral oximetry during thoracic surgery correlates with postoperative complications. Br J Anaesth 2009;103:811-6.

[11] Tang L, Kazan R, Taddei R, Zaouter C, Cyr S, Hemmerling TM. Reduced cerebral oxygen saturation during thoracic surgery predicts early postoperative cognitive dysfunction. Br J Anaesth 2012;108:623-9.

[12] Casati A, Fanelli G, Pietropaoli P, Proietti R, Tufano R, Danelli G, et al Continuous monitoring of cerebral oxygen saturation in elderly patients undergoing major abdominal surgery minimizes brain exposure to potential hypoxia. Anesth Analg 2005;101:740-7.

[13] Casati A, Fanelli G, Pietropaoli P, Proietti R, Tufano R, Montanini S, et al. Monitoring cerebral oxygen saturation in elderly patients undergoing general abdominal surgery: a prospective cohort study. Eur J Anaesthesiol 2007; 24:59-65.

[14] De Deyne C, Joly LM, Ravussin P. Les nouveaux agents volatils halogénés en neuro-anesthésie : quelle place pour le sévoflurane ou le desflurane ? Ann Fr Anesth Reanim 2004;23:367-74.
[15] Dagal A, Lam AM. Cerebral autoregulation and anaesthesia. Curr Opin Anaesthesiol 2009:22:547-52.

[16] Engelhard K, Werner C. Inhalational or intravenous anaesthetics for craniotomies? Pro inhalational. Curr Opin Anaesthesiol 2006;19:504-8.

[17] Munoz HR, Nunez GE, de la Fuente JE, Campos MG. The effect of nitrous oxide on jugular bulb oxygen saturation during remifentanil plus target-controlled infusion propofol or sevoflurane in patients with brain tumors. Anesth Analg 2002;94:389-92.

[18] Petersen KD, Landsfeldt U, Cold GE, Petersen CB, Mau S, Hauerberg J, et al. Intracranial pressure and cerebral haemodynamic in patients with cerebral tumors: a randomized prospective study of patients subjected to craniotomy in propofol-fentanyl, isoflurane-fentanyl, or sevoflurane-fentanyl anaesthesia. Anesthesiology 2003;98:329-36.

[19] Jeong H, Jeong S, Lim HJ, Lee J, Yoo KY. Cerebral oxygen saturation measured by near-infrared spectroscopy and jugular venous bulb oxygen saturation during arthroscopic shoulder surgery in beach chair position under sevofluranenitrous oxide or propofol-remifentanil anaesthesia. Anesthesiology 2012; 116:1047-56.

[20] Cho S, Fujigaki T, Uchiyama Y, Fukusaki M, Shibata O, Sumikawa K. Effects of sevoflurane with and without nitrous oxide on human cerebral circulation. Transcranial Doppler study. Anesthesiology 1996;85:755-60.

[21] Klein KU, Fukui K, Schramm P, Stadie A, Fischer G, Werner C, et al. Human cerebral microcirculation and oxygen saturation during propofol-induced reduction of bispectral index. Br J Anaesth 2011;107:735-41.

[22] Moerman AT, De Hert SG. Utility of near-infrared spectroscopy for assessing cerebral oxygen saturation during beach chair position. Anesthesiology 2012; 117:1395 [letter].

[23] Elizabeth AM, Frost M. Cerebral oximetry: emerging applications for an established technology. Anesthesiol News 2012;38:10.

[24] Philip BK, Lombard LL, Roaf ER, Drake AF, Calalang I, Philip JH. Comparison of vital capacity induction with sevoflurane to intravenous induction with propofol for adult ambulatory anesthesia. Anesth Analg 1999;89:623-7.

[25] Edmonds Jr HL, Ganzel BL, Austin 3rd EH. Cerebral oximetry for cardiac and vascular surgery. Semin Cardiothorac Vasc Anesth 2004;8:147-66.

[26] Casati A, Spreafico E, Putzu M, Fanelli G. New technology for noninvasive brain monitoring: continuous cerebral oximetry. Minerva Anestesiol 2006;72: 605-25.

[27] Fischer GWGS. Cerebral oximetry in cardiac and major vascular surgery. HSR Proceedings in Intensive Care and Cardiovascular Anaesthesia 2010;2:249-56

[28] Moerman AT, De Hert SG, Jacobs TF, De Wilde LF, Wouters PF. Cerebral oxygen desaturation during beach chair position. Eur I Anaesthesiol 2012;29:82-7.

[29] Murphy GS, Szokol JW, Marymont JH, Greenberg SB, Avram MJ, Vender JS, et al. Cerebral oxygen desaturation events assessed by near-infrared spectroscopy during shoulder arthroscopy in the beach chair and lateral decubitus positions. Anesth Analg 2010;111:496-505.

[30] Hemmerling TM, Bluteau MC, Kazan R, Bracco D. Significant decrease of cerebral oxygen saturation during single-lung ventilation measured using absolute oximetry. Br J Anaesth 2008;101:870-5.

[31] Kanaya N, Hirata N, Kurosawa S, Nakayama M, Namiki A. Differential effects of propofol and sevoflurane on heart rate variability. Anesthesiology 2003;98: 34-40.

[32] Fassoulaki A, Kaliontzi H, Petropoulos G, Tsaroucha A. The effect of desflurane and sevoflurane on cerebral oximetry under steady-state conditions. Anesth Analg 2006;102:1830-5.

[33] Dahyot-Fizelier C, Frasca D, Debaene B. Pour ou contre les halogénés en neuroanesthésie pour chirurgie intracrânienne. Ann Fr Anesth Reanim 2012;31:e229-34. 